\title{
PREDICTING SPRAY DRIFT FROM BACKPACK AND UTV SPRAYING
}

\author{
M. E. Teske, H. W. Thistle, G. J. Kees
}

ABSTRACT. This article summarizes the development and predictions of a Lagrangian-based computer model applied to recent field data on backpack and utility vehicle spraying. Model agreement with data supports the usefulness of the model for the tested conditions, and provides the USDA Forest Service and other agencies with a simple-to-use numerical tool to estimate spray drift from similar single-nozzle applications.

Keywords. AGDISP, Backpack, Drift, Model, Utility vehicle (UTV).

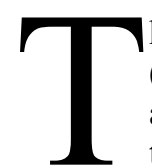
he USDA Forest Service (FS) uses backpack (knapsack) and utility vehicles (UTVs) for spot and roadside spraying in federal lands throughout the U.S. In some countries in the rest of the world, these sprayers are the prime application technique for crop protection, especially for smallholder farmers. Apart from the benefits of appropriate pesticide use in agriculture, spray drift presents a danger to not only the applicator but also the environment, a danger that is rarely considered in these applications but nonetheless always present. Recent studies, for example, address pesticide practice with knapsack spraying (Snelder et al., 2008; García-Santos et al., 2015).

As part of the effort to meet the requirements of the National Environmental Policy Act (NEPA, 1969), federal land managers are required to assess the risks of all pesticide use on federal lands. The FS responds to NEPA by producing formal risk assessments. A recent field study (Thistle et al., 2017) collected data to characterize such risks with regard to backpack and UTV spraying. This article summarizes the development of a computer model to predict these data and thereby support applicable future FS risk assessments.

\section{Approach}

Backpack and UTV spraying often involves a single nozzle, releasing spray droplets as the applicator either walks

(c) (i) $\Theta$ The authors have paid for open access for this article. This $C_{\mathrm{BY}} \mathrm{NC}$ No work is licensed under a Creative Commons AttributionNonCommercial-NoDerivatives 4.0 International License https://creative commons.org/licenses/by-nc-nd/4.0/

Submitted for review in January 2018 as manuscript number MS 12787; approved for publication by the Machinery Systems Community of ASABE in July 2018.

Mention of company or trade names is for description only and does not imply endorsement by the USDA. The USDA is an equal opportunity provider and employer.

The authors are Milton E. Teske, Senior Associate, Continuum Dynamics, Inc., Ewing, New Jersey; Harold W. Thistle, Program Manager, USDA Forest Service, Morgantown, West Virginia; Gary J. Kees, Engineer, USDA Forest Service, Missoula, Montana. Corresponding author: Milton E. Teske, Continuum Dynamics, Inc., 34 Lexington Avenue, Ewing, NJ 08616; phone: 609-538-0444; e-mail: milt@continuum-dynamics.com. with a handheld spray wand, often walking into the spray, or drives a utility vehicle with a spray nozzle positioned at the rear. It may be seen that a model that computes spray application from a single nozzle represents a significant departure from a model (such as AGDISP) that computes spray application from multiple nozzles on a spray boom. Obvious differences between these two application approaches include spray release height, forward speed, and the importance of initial droplet velocity exiting the nozzle. The deposition from multiple nozzles on a spray boom (aerial and ground) overlaps to produce a near-uniform ground deposition pattern beneath the nozzles. With a single nozzle, the geometry of the spray pattern is important, as more spray material deposits down the centerline of the nozzle.

The Lagrangian approach developed for the aerial application module in AGDISP (Bilanin et al., 1989; Teske et al., 2003) tracks the motion of spray droplets released from nozzles on a spray boom, with one droplet released at the centerline of each nozzle for every droplet size in the drop size distribution. This modeling approach has been adapted here for a single-nozzle application, releasing multiple droplets uniformly across the nozzle exit spray cross-sectional shape.

In their simplest form, the equations governing the mean transport of a released droplet are:

$$
\begin{gathered}
\frac{d^{2} X_{i}}{d t^{2}}=\left[U_{i}-V_{i}\right]\left[\frac{1}{\tau_{p}}\right]+g_{i} \\
\frac{d X_{i}}{d t}=V_{i}
\end{gathered}
$$

where $t$ is time (s), $X_{i}$ is the location of the droplet (m), $V_{i}$ is the droplet velocity $\left(\mathrm{m} \mathrm{s}^{-1}\right), U_{i}$ is the background crosswind $\left(\mathrm{m} \mathrm{s}^{-1}\right), g_{i}$ is gravity $\left(\mathrm{m} \mathrm{s}^{-2}\right)$, and $\tau_{p}$ is the droplet relaxation time (s):

$$
\tau_{p}=\frac{4}{3} \frac{D \rho}{C_{D} \rho_{a}\left|U_{i}-V_{i}\right|}
$$

where $D$ is the droplet diameter $(\mu \mathrm{m}), \rho$ is the droplet density $\left(\mathrm{kg} \mathrm{m}^{-3}\right), C_{D}$ is the droplet drag coefficient (nondimensional), and $\rho_{a}$ is the air density $\left(\mathrm{kg} \mathrm{m}^{-3}\right)$. 
Even though droplets are released close to the ground, droplet evaporation is included in the model for completeness. The evaporation model follows the diameter-squared law of Trayford and Welch (1977), with an extension for the recent addition of droplet cloud effects:

$$
1-\frac{D^{2}}{D_{O}{ }^{2}}=a \frac{t}{\tau_{e}}\left[1+b \frac{t}{\tau_{e}}\right]
$$

where $D_{O}$ is the initial droplet diameter $(\mu \mathrm{m}), a=0.223$ and $b=0.314$ are evaluated from recent evaporation tests (Teske et al., 2018), and $\tau_{e}$ is the evaporation time scale of the droplet (s):

$$
\tau_{e}=\frac{2 D_{O}{ }^{2}}{\lambda \Delta \Theta \mathrm{Sh}}
$$

where $\lambda$ is the evaporation rate $\left(\mu \mathrm{m}^{2} \mathrm{~s}^{-1}{ }^{\circ} \mathrm{C}^{-1}\right), \Delta \Theta$ is the wet bulb temperature depression $\left({ }^{\circ} \mathrm{C}\right), \mathrm{Sh}=2\left(1+0.27 \mathrm{Re}^{1 / 2}\right)$ is the Sherwood number, $\operatorname{Re}=D\left|U_{i}-V_{i}\right| / \mathrm{v}_{a}$ is the Reynolds number, and $v_{a}$ is the kinematic viscosity of air $\left(\mathrm{m}^{2} \mathrm{~s}^{-1}\right)$.

In a neutral atmospheric surface layer, the horizontal velocity $V\left(\mathrm{~m} \mathrm{~s}^{-1}\right)$ is assumed to follow a logarithmic profile:

$$
V=V_{r} \frac{\ln \left[\left(z+z_{o}\right) / z_{o}\right]}{\ln \left[\left(z_{r}+z_{o}\right) / z_{o}\right]}
$$

where $V_{r}$ is the horizontal velocity $\left(\mathrm{m} \mathrm{s}^{-1}\right)$ at the reference height $z_{r}(\mathrm{~m}), z$ is vertical distance $(\mathrm{m})$, and $z_{o}$ is surface roughness $(\mathrm{m})$. With a linear integral scale of turbulence $(\Lambda=0.65 z)$, the turbulence level (Donaldson, 1973; Lewellen, 1977) becomes:

$$
q_{\text {wind }}^{2}=0.845\left[\frac{V_{r}}{\ln \left[\left(z_{r}+z_{o}\right) / z_{o}\right]}\right]^{2}
$$

Droplet trajectories are followed from their release at the nozzle until they either deposit on the ground or move beyond the downwind plane of interest. This modeling approach was vetted against the extensive Spray Drift Task Force aerial field data (Teske et al., 2002).

\section{MeTHOD}

Field trial conditions are summarized in tables 1, 2, and 3. Backpack spraying was conducted with a Solo 425 piston pump sprayer; UTV spraying was conducted with a King's KS50P6, 189 L high-volume turf and tree sprayer skid mounted on a John Deere Gator. The applicable droplet sizes $\left(D_{v 0.1}, D_{v 0.5}\right.$, and $D_{v 0.9}$ in $\left.\mu \mathrm{m}\right)$ were provided by A. J. Hewitt for the XR-11003 and B. K. Fritz for the Boominator 1400FM (personal communications, 2017). Drop size distributions were developed with the use of the upper limit log normal function (Mugele and Evans, 1951). A crosswind direction was assumed for all simulations (wind direction was not recorded during the field study). Surface roughness was assumed to be $1 / 30$ of the measured grass height of $0.15 \mathrm{~m}$, or $0.005 \mathrm{~m}$. In tables 2 and 3 , wind speeds were recorded at a height of $2.3 \mathrm{~m}$ in trials 1 to 10 and at a height of $2.0 \mathrm{~m}$ in
Table 1. Test conditions for backpack and UTV single-nozzle field studies.

\begin{tabular}{ccc}
\hline Parameter & Backpack & UTV \\
\hline Nozzle type & XR-11003 & Boominator \\
& fan nozzle & $1400 \mathrm{FM}$ \\
Nozzle pressure (bar) & 1.448 & 2.413 (average) \\
Ideal spray exit speed $\left(\mathrm{m} \mathrm{s}^{-1}\right)$ & 17.0 & 22.0 (average) \\
Nozzle direction & Straight down & Straight down \\
Spray fan angle $\left({ }^{\circ}\right)$ & 110.0 & 141.2 \\
Nonvolatile/active fraction & 0.005 & 0.005 \\
Spray release height (m) & 0.84 & 1.07 \\
Swath width $(\mathrm{m})$ & 2.40 & 6.08 \\
Spraying speed $\left(\mathrm{m} \mathrm{s}^{-1}\right)$ & 1.40 & 1.45 \\
& $($ walking) & $($ John Deere Gator) \\
$D_{v 0.1}(\mu \mathrm{m})$ & 128.0 & $237.8,206.5$ \\
$D_{v 0.5}(\mu \mathrm{m})$ & 283.0 & $670.9,596.2$ \\
$D_{v 0.9}(\mu \mathrm{m})$ & 488.0 & $1382.6,1359.0$ \\
\hline
\end{tabular}

Table 2. Test conditions for backpack single-nozzle (XR-11003) field studies.

\begin{tabular}{cccc}
\hline $\begin{array}{c}\text { Trial } \\
\text { Number }\end{array}$ & $\begin{array}{c}\text { Wind Speed } \\
\left(\mathrm{m} \mathrm{s}^{-1}\right)\end{array}$ & $\begin{array}{c}\text { Temperature } \\
\left({ }^{\circ} \mathrm{C}\right)\end{array}$ & $\begin{array}{c}\text { Relative Humidity } \\
(\%)\end{array}$ \\
\hline 1 & 0.6 & 8.6 & 43.5 \\
3 & 0.9 & 15.7 & 25.7 \\
5 & 3.0 & 21.1 & 17.9 \\
7 & 2.2 & 22.4 & 12.9 \\
9 & 2.6 & 23.1 & 11.7 \\
11 & 1.5 & 8.3 & 49.0 \\
13 & 2.5 & 11.1 & 43.7 \\
15 & 3.1 & 15.1 & 35.2 \\
17 & 3.1 & 14.1 & 39.6 \\
19 & 1.5 & 12.5 & 50.5 \\
\hline
\end{tabular}

Table 3. Test conditions for UTV single-nozzle (Boominator) field studies.

\begin{tabular}{cccc}
\hline $\begin{array}{c}\text { Trial } \\
\text { Number }\end{array}$ & $\begin{array}{c}\text { Wind Speed } \\
\left(\mathrm{m} \mathrm{s}^{-1}\right)\end{array}$ & $\begin{array}{c}\text { Temperature } \\
\left({ }^{\circ} \mathrm{C}\right)\end{array}$ & $\begin{array}{c}\text { Relative Humidity } \\
(\%)\end{array}$ \\
\hline 2 & 0.5 & 12.5 & 34.1 \\
4 & 1.1 & 18.8 & 21.3 \\
6 & 2.0 & 21.5 & 14.4 \\
8 & 3.0 & 23.1 & 12.3 \\
10 & 2.3 & 21.5 & 13.2 \\
12 & 0.8 & 8.3 & 56.0 \\
14 & 1.8 & 13.9 & 32.8 \\
16 & 5.0 & 14.1 & 35.8 \\
18 & 4.2 & 12.1 & 53.0 \\
20 & 2.4 & 11.7 & 52.9 \\
\hline
\end{tabular}

trials 11 to 20 . Temperature and relative humidity were recorded at a height of $2.0 \mathrm{~m}$ in all trials. The values shown here were duplicated from Thistle et al. (2017), while the wind speed values were added from an Excel spreadsheet provided by co-author HWT. The field study was conducted at an altitude of $975 \mathrm{~m}$ a.s.1., or an atmospheric standard pressure of $901.47 \mathrm{mb}$.

The spray release heights and swath widths shown in table 1 vary slightly from values found in Thistle et al. (2017). The release heights were corrected from an original estimate of $0.80 \mathrm{~m}$ for both backpack and UTV from project notes recorded by co-author GJK. Swath widths were observed visually by Thistle et al. (2017) but were deduced from the nominal spray angle of $110^{\circ}$ for the XR-11003 and information from the Boominator website (www.boominator.com) identifying that a laboratory testing height of $0.91 \mathrm{~m}$ resulted in a spray width of $5.18 \mathrm{~m}$ for a full pattern nozzle, or a spray angle of $141.2^{\circ}$, thereby concluding that a release height of $1.07 \mathrm{~m}$ would result in a swath width of $6.08 \mathrm{~m}$. 
The ideal spray exit speeds, for a discharge coefficient of $C_{d}=1$, were computed from the square root of 200 times the nozzle pressure in bar. Both nozzles were pointed straight down, as seen in the photographs in Thistle et al. (2017). Drop size distributions are plotted in figure 1 .

The trials positioned three types of deposition collectors on a grid from $6 \mathrm{~m}$ upwind of the application direction to $25 \mathrm{~m}$ downwind: Mylar sheets, water-sensitive paper (for confirmation of in-swath coverage levels), and artificial foliage. Test results were averaged for each of the trials over four collection lines placed perpendicular to the application direction (see Thistle et al., 2017 for details).

Aircraft vortices dominate the wake flow field in the AGDISP aerial model, such that the initial speed of the released droplets from the nozzles is unimportant to the deposition solution. For backpack and UTV spraying, no such dominant wake velocity field exists (rather, droplet motion is controlled by the nozzle exit speed and gravity). The exit speed of the droplets from the nozzle fixes the initial velocity of the droplets and generates an air entrainment velocity that perpetuates the downward movement of the droplets to the ground. To simulate spray release from a single nozzle correctly, droplets were positioned systematically across the nozzle exit, spanning the spray angle from the nozzle.

Consequently, an important parameter in backpack and UTV spraying is the initial droplet velocity from the nozzle (if this velocity is not included, none of the droplets reach the ground near the application area because of crosswind). It is generally assumed in ground spraying (Sidahmed, 1996) that:

$$
U_{\text {exit }}=C_{d}\left(\frac{2 P}{\rho}\right)^{0.5}
$$

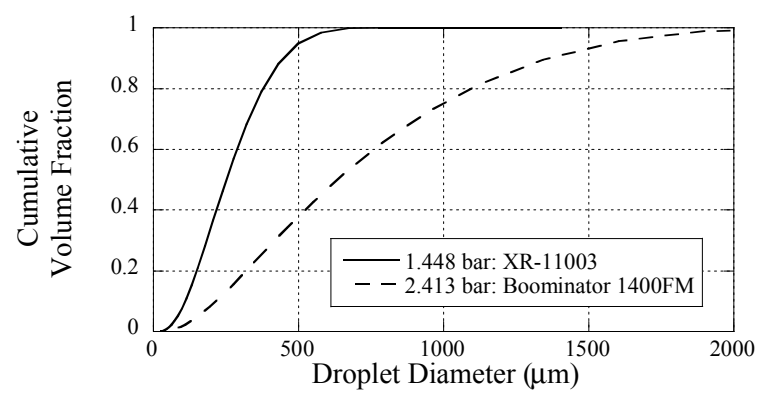

Figure 1. Drop size distributions for the XR-11003 and Boominator 1400FM nozzles used by Thistle et al. (2017). The Boominator drop size distribution is the average of the two distributions measured for the field study. where $U_{\text {exit }}$ is the droplet exit velocity $\left(\mathrm{m} \mathrm{s}^{-1}\right)$ from the nozzle, $P$ is the nozzle pressure (bar), and $C_{d}$ is the discharge coefficient (nondimensional). The nozzle discharge coefficient $\left(C_{d}\right)$ must be developed from laboratory measurements. Table 4 summarizes the results of a literature search for discharge coefficients, including all available versions of XR11002 and 11003 nozzles at pressures comparable to the spray pressure used in the field study. From these data, the average discharge coefficient is 0.85 , with a standard deviation of 0.11 .

The discharge coefficient for the Boominator 1400FM has never been determined, even by the manufacturer, and must be assumed here. From observations during the field trials, it was conjectured that the exit velocity from the Boominator was approximately half that of the XR-11003. Post et al. (2017) concluded from their testing that the discharge coefficient decreased with increasing pressure and increased with increasing nozzle size, but with exceptions. Thus, use of equation 8 (where $C_{d}$ is inversely proportional to the square root of pressure) gives a discharge coefficient of 0.33 , based on the average of the two tank pressures and the XR-11003 average discharge coefficient. Variations in $C_{d}$ are explored in a sensitivity study later in this article.

As droplets leave the nozzle, they feel the effect of entrainment by vortices formed in the air on either side of the liquid jet. This additional downward motion was studied previously by Briffa and Dombrowski (1966) and Miller and Hadfield (1989), resulting in the entrainment velocity $W_{\text {entr }}$ $\left(\mathrm{m} \mathrm{s}^{-1}\right)$ :

$$
W_{\text {entr }}=C_{\text {entr }} U_{\text {exit }}\left(\frac{L}{h}\right)^{0.57}
$$

where $L$ is the length of the liquid sheet $(\mathrm{m}), h$ is the distance (m) below the nozzle, and $C_{\text {entr }}$ is a modeling constant (nondimensional). Miller and Hadfield (1989) determined that the best agreement with their ground sprayer data gave $C_{\text {entr }}=0.88$. The parameter $L$ (the distance traveled by the sheet before breaking into droplets) has been studied occasionally and depends on nozzle pressure, nozzle design, spray liquid involved, and the defined "edge" of the sheet and the beginning of the droplets. $L$ is known to be sensitive to nozzle angle, orifice size, nozzle type, and liquid viscosity. From the data summarized in table 5, the presumed average liquid sheet length for the XR-11003 nozzle was $5.6 \mathrm{~cm}$, with a standard deviation of $1.5 \mathrm{~cm}$. A length of $10 \mathrm{~cm}$ was assumed for the Boominator 1400FM. Variations in $L$ are also explored in the sensitivity study.

Table 4. Summary of available references on discharge coefficient for tank pressures comparable to field test conditions. Nozzles include TeeJet Extended Range Flat Tip (XR), Greenleaf Standard Tip (ST), Turbo TeeJet Wide Angle Flat Tip (TT), and Albuz Standard Flat Tip (APE).

\begin{tabular}{cccc}
\hline Nozzle & Pressure (bar) & $C_{d}$ & Source \\
\hline XR-11002 & 1.5 & 0.80 & Dorr et al. (2013) computed from their data \\
ST-11002 & 3.0 & 0.75 & Wang et al. (2015) computed from their data \\
ST-11003 & 3.0 & 0.79 & Wang et al. (2015) computed from their data \\
ST-11001 & 2.07 & 0.90 & Post et al. (2017) \\
ST-11003 & 2.07 & 0.96 & Post et al. (2017) \\
ST-11002 & 2.0 & 0.98 & Sayinci (2016) \\
ST-11003 & 2.0 & 0.92 & Sayinci (2016) \\
APE-11002 & 2.0 to 4.0 & 0.88 & Sayinci (2015) \\
APE-11003 & 2.0 to 4.0 & 0.88 & Sayinci (2015) \\
TT-11002 & 1.5 & 0.62 & Dorr et al. (2013) computed from their data \\
Boominator 1400FM & 2.413 (average) & 0.33 & Estimated \\
\hline
\end{tabular}


Table 5. Summary of available references on liquid sheet length and spray angle.

\begin{tabular}{cccc}
\hline Nozzle & $L(\mathrm{~cm})$ & Spray Angle $\left(^{\circ}\right)$ & Source \\
\hline ST-11002 & 3.9 & 116.0 & Wang et al. (2015) \\
ST-11003 & 4.8 & 119.0 & Wang et al. (2015) \\
Test assumption & Less than 12.0 & - & Dorr et al. (2013) \\
XR-11002 & - & 124.8 & Dorr et al. (2013) computed from their data \\
TT-11002 & - & 122.8 & Dorr et al. (2013) computed from their data \\
Typical nozzle & Less than 10.0 & - & M. C. Butler Ellis (personal communication, 2017) \\
Laboratory nozzle & Less than 4.0 & - & Stapper et al. (1992) \\
Boominator 1400FM & 7.0 to 14.0 & B. Fritz (personal communication, 2018)
\end{tabular}

Equation 9 was developed for fan nozzles and is assumed to be approximately correct for the Boominator 1400FM. Table 5 also includes spray angle measurements, although the values shown in table 1 will be used in the analysis.

Equation 9 models the entrainment velocity generated by flow from a stationary nozzle. In the field applications discussed here, the nozzle continues to move along the application line, no longer providing droplet downwash from the nozzle at its earlier locations, and suggesting that the entrainment vortices decay quickly. These vortices are disrupted by the movement of the backpack applicator walking through the released spray, and by the bluff body effects directly behind the UTV sprayer (the generation of weak wake vortices). With the XR-11003 nozzle pointed straight down, the backpack applicator walks through the spray as it hits the ground, disturbing the spray and its entrainment velocity field. Similarly, the bluff body effect behind the John Deere Gator almost immediately generates low-velocity symmetrical vortices (Khalighi et al., 2001) that quickly disrupt the entrainment flow field. For the data analyzed here, and given the possible interference of the entrainment velocity by the applicator or the wake of the Gator, it was assumed that the entrainment velocity fell to zero within $0.1 \mathrm{~s}$ after spray release.

\section{RESULTS}

Model predictions were made for each of the 20 trials reported by Thistle et al. (2017) for the test conditions summarized in tables 1,2 , and 3 . Consistent with the presentation approach in Thistle et al. (2017), which included plots of the data for all of the meteorological conditions tested, only the averages of these predictions were compared with the averages of the two sets of trial data. Model comparisons are plotted in figures 2 and 3 for the XR-11003 and Boominator 1400FM nozzles, respectively. Plotted with the backpack data and model prediction are the test results from Holterman et al. (1997) for XR-11002 and XR-11004 nozzles (identical deposition patterns) and from García-Santos et al. (2015) for a knapsack sprayer with a high-discharge hollowcone nozzle. Plotted with the UTV data and model prediction are the all-terrain vehicle (ATV) data measured by Kees (2008) under similar testing conditions.

The goal of the data collection and modeling was to develop a conservative model for simulating the drift from these two application techniques. It may be seen from figures 2 and 3 that the model results tend to bound the data, especially at downwind distances greater than $10 \mathrm{~m}$. As noted by Thistle et al. (2017), the deposition levels measured on the Mylar cards required a correction for mass balance, yet still recovered somewhat lower deposition levels than the

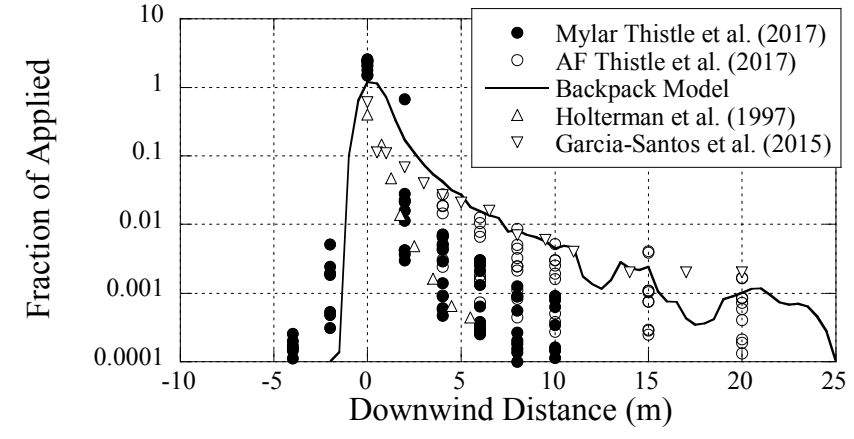

Figure 2. Comparison of the average model deposition prediction for the ten backpack data trials identified by the conditions in tables 1 and 2, for Mylar and AF (artificial foliage), from Thistle et al. (2017). Additional data were collected from Holterman et al. (1997) and GarcíaSantos et al. (2015). The centerline of the backpack sprayer was at a downwind distance of $0 \mathrm{~m}$.

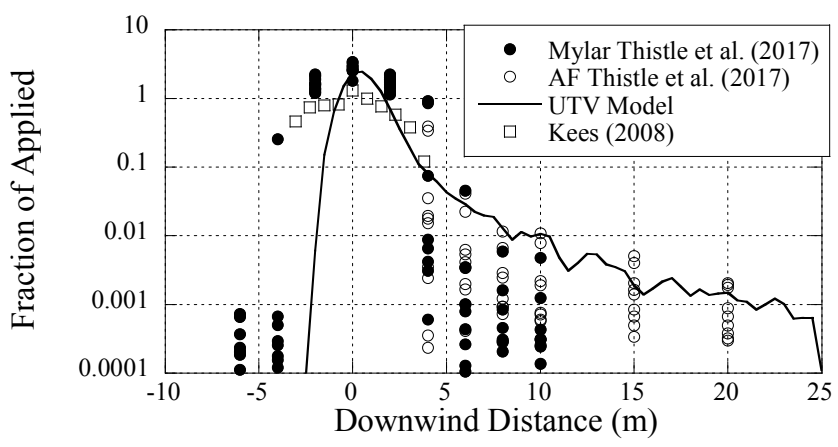

Figure 3. Comparison of the average model deposition prediction for the ten utility vehicle (UTV) data trials identified by the conditions in tables 1 and 3, for Mylar and AF (artificial foliage), from Thistle et al. (2017). Additional data were collected from Kees (2008). The centerline of the John Deere Gator was positioned at a downwind distance of $\mathbf{0 ~ m}$.

deposition levels measured with the artificial foliage (whose mass accountancy was within expected error bars).

\section{DISCUSSION}

The results shown in figures 2 and 3 indicate that the model does not predict deposition on the upwind side of the spray release location, but the downwind deposition bounds the data collected by Thistle et al. (2017) for the artificial foliage collectors. The model behavior is also consistent with the data collected by García-Santos et al. (2015) out to $20 \mathrm{~m}$ (backpack) and by Kees (2008) out to the extent of his data. Because of the low spray release height and atmospheric conditions during the tests, evaporation played no role in the behavior of the released droplets, accounting for an average evaporation of only $0.75 \%$ of the volatile mass. 


\section{MODEL ACCURACY}

Model accuracy for spray collection on the artificial foliage can be suggested by the ratio of the predicted deposition at the six test locations $(4,6,8,10,15$, and $20 \mathrm{~m}$ downwind) to the peak data collected at these locations, as shown in figure 4. It may be seen that the model tends to match the data between 5 and $10 \mathrm{~m}$ but underpredicts the data farther downwind.

Model predictions beyond $10 \mathrm{~m}$ are the result of the impaction of released droplets captured by the crosswind and carried downwind. The extension of these predictions to downwind distances beyond those tested can be made by fitting the data to exponential functions (the same approach used to extend deposition predictions in AGDISP). Applying this approach to the two sets of data resulted in the following expressions for estimated deposition level in fraction of applied (FOA, nondimensional) and the comparisons shown in figure 5:

$$
\begin{gathered}
\text { FOA }=0.0128 \exp (-0.1467 Y) \\
\mathrm{R}^{2}=0.673 \text { (backpack) } \\
\text { FOA }=0.0448 \exp (-0.1841 Y) \\
\mathrm{R}^{2}=0.815(\mathrm{UTV})
\end{gathered}
$$

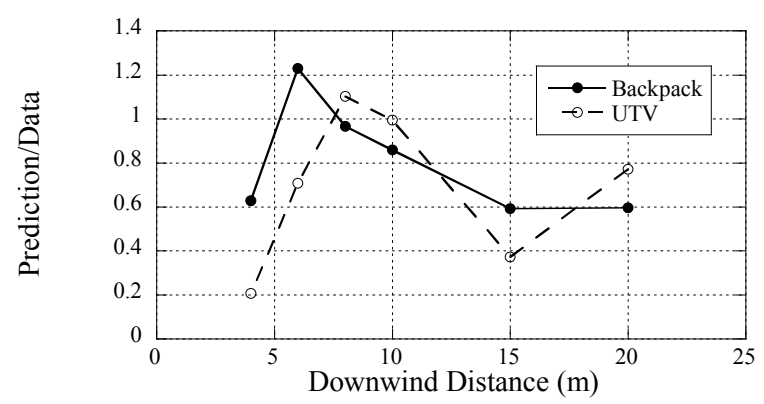

Figure 4. Ratio of backpack and UTV model predictions to the bounding data from Thistle et al. (2017).

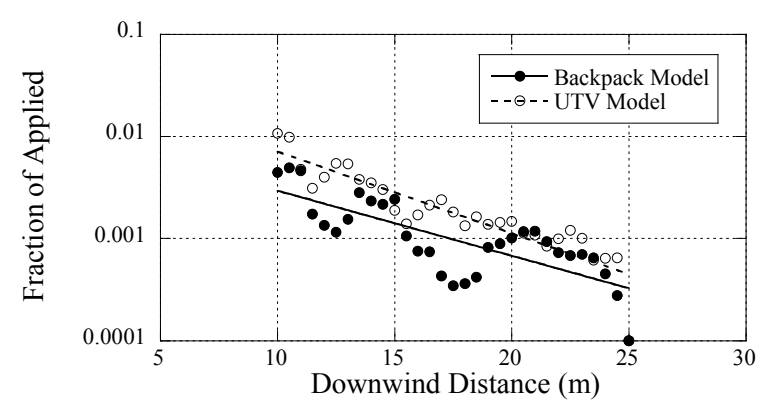

Figure 5. Comparison of backpack and UTV model predictions (solid and open circles, respectively) with the exponential curve fits identified in equations 10 and 11 (solid line for backpack, dashed line for UTV). where $Y$ is the downwind distance $(\mathrm{m})$. By contrast, an AGDISP prediction of the deposition from a typical aerial application at a release height of $3 \mathrm{~m}$ does not reach a fraction of applied of 0.0001 until $2 \mathrm{~km}$ downwind. That same level is achieved by $31.5 \mathrm{~m}$ for backpack spraying and by $32.6 \mathrm{~m}$ for UTV spraying.

\section{Model Sensitivity STUdY}

Because most of the deposition occurred near the spray nozzles (due to the spray release height), the total deposition out to $10 \mathrm{~m}$ was the variable of interest in the sensitivity study. Comparisons were made by considering the effect of changing one variable at a time, comparing the logarithm of the base model result (the inputs used to generate figs. 2 and 3 ) to the logarithm of the changed variable result. This approach emphasized the differences in deposition values that were close to the total amount deposited and made lower deposition values as important as higher ones. The results (ten trials each for backpack and UTV) for the variables considered are shown in table 6. For example, a decrease of $10 \%$ in wind speed (the ten numbers shown in table 2 for the backpack) resulted in an $18.9 \%$ average increase in total deposition out to $10 \mathrm{~m}$ downwind.

As with sensitivity studies for aerial application (Teske and Barry, 1993), wind speed, release height, and drop size distribution (nozzle pressure) are most significant, increasing deposition out to $10 \mathrm{~m}$ (above the base model results) with a decrease in their values, and decreasing deposition with an increase in their values. Decreasing wind speed increases the likelihood that more spray droplets deposit closer to the nozzle, while increasing wind speed moves more spray droplets farther downwind. A decrease in release height brings spray droplets closer to the ground, while an increase in release height allows them to move farther downwind before depositing. A decrease in nozzle pressure increases deposition, as larger droplets are formed and deposit closer to the nozzle, while an increase in nozzle pressure decreases deposition, as smaller droplets are formed and drift farther downwind before depositing. Finally, an increase or decrease in the discharge coefficient and sheet length causes minimal changes to the deposition. These results appear consistent with previous aerial and ground model predictions.

\section{Conclusions}

Deposition predictions based on a simplified droplet trajectory model have been shown to compare favorably with data of spray material released from single-nozzle backpack and UTV sprayers. This article highlights this comparison and suggests that the model can be used for a quick estimate

\begin{tabular}{|c|c|c|c|c|}
\hline \multirow[b]{2}{*}{ Variable } & \multicolumn{2}{|c|}{ Backpack } & \multicolumn{2}{|c|}{ UTV } \\
\hline & $-10 \%$ & $+10 \%$ & $-10 \%$ & $+10 \%$ \\
\hline Wind speed & $18.9 \%$ increase & $14.1 \%$ decrease & $22.1 \%$ increase & $13.7 \%$ decrease \\
\hline Spray release height & $33.2 \%$ increase & $20.6 \%$ decrease & $28.8 \%$ increase & $18.0 \%$ decrease \\
\hline Discharge coefficient $\left(C_{d}\right)$ & $2.0 \%$ decrease & $2.0 \%$ increase & $1.1 \%$ decrease & $1.0 \%$ increase \\
\hline Sheet length $(L)$ & $1.3 \%$ decrease & $1.4 \%$ increase & $1.6 \%$ decrease & $1.4 \%$ increase \\
\hline Nozzle pressure & $33.3 \%$ increase & $24.2 \%$ decrease & $11.8 \%$ increase & $19.9 \%$ decrease \\
\hline
\end{tabular}
of deposition and drift potential from pesticide applications by either approach.

Table 6. Percentage change in deposition out to $10 \mathrm{~m}$ in response to $10 \%$ changes in several backpack and UTV parameters. 


\section{REFERENCES}

Bilanin, A. J., Teske, M. E., Barry, J. W., \& Ekblad, R. B. (1989). AGDISP: The aircraft spray dispersion model, code development and experimental validation. Trans. ASAE, 32(1), 327-334. https://doi.org/10.13031/2013.31005

Briffa, F. E., \& Dombrowski, N. (1966). Entrainment of air into a liquid spray. AIChE J., 12(4), 708-717. https://doi.org/10.1002/aic.690120416

Donaldson, C. duP. (1973). Atmospheric turbulence and the dispersal of atmospheric pollutants. In D. A. Haugen (Ed.), Proc. AMS Workshop on Micrometeorology. Boston, MA: Science Press.

Dorr, G. J., Hewitt, A. J., Adkins, S. W., Hanan, J., Zhang, H., \& Noller, B. (2013). A comparison of initial spray characteristics produced by agricultural nozzles. Crop Prot., 53, 109-117. https://doi.org/10.1016/j.cropro.2013.06.017

García-Santos, G., Feola, G., Nuyttens, D., \& Diaz, J. (2015). Drift from the use of hand-held knapsack pesticide sprayers in Boyaca (Colombian Andes). J. Agric. Food. Chem., 64(20), 3990-3998. https://doi.org/10.1021/acs.jafc.5b03772

Holterman, H. J., van de Zande, J. C., Porskamp, H. A. J., \& Huijsmans, J. F. M. (1997). Modelling spray drift from boom sprayers. Comput. Electron. Agric., 19(1), 1-22. https://doi.org/10.1016/S0168-1699(97)00018-5

Kees, G. (2008). Field evaluation of a constant-rate herbicide sprayer for ATVs and UTVs. 0824-2802-MTDC. Missoula, MT: USDA Forest Service, Missoula Technology and Development Center.

Khalighi, B., Zhang, S., Koromilas, C., Balkanyi, S. R., Bernal, L. P., Iaccarino, G., \& Moin, P. (2001). Experimental and computational study of unsteady wake flow behind a bluff body with a drag reduction device. SAE Technical Paper 2001-011042. Warrendale, PA: SAE. https://doi.org/10.4271/2001-011042

Lewellen, W. S. (1977). Use of invariant modeling. In W. Frost \& T. H. Moulden (Eds.), Handbook of turbulence (pp. 237-280). Elmsford, NY: Plenum Press.

Miller, P. C. H., \& Hadfield, D. J. (1989). A simulation model of the spray drift from hydraulic nozzles. J. Agric. Eng. Res., 42(2), 135-147. https://doi.org/10.1016/0021-8634(89)90046-2

Mugele, R. A., \& Evans, H. D. (1951). Droplet size distribution in sprays. Ind. Eng. Chem., 43(6), 1317-1324. https://doi.org/10.1021/ie50498a023

NEPA. (1969). National Environmental Policy Act (42 U.S.C. § 4321 et seq.). Washington, DC: U.S. Congress.
Post, S. L., Roten, R. L., \& Connell, R. J. (2017). Discharge coefficients of flat-fan nozzles. Trans. ASABE, 60(2), 347-351. https://doi.org/10.13031/trans.12064

Sayinci, B. (2015). Effect of strainer type, spray pressure, and orifice size on the discharge coefficient of standard flat-fan nozzles. Turkish J. Agric. Forestry, 39(5), 692-704. https://doi.org/10.3906/tar-1410-89

Sayinci, B. (2016). The influence of strainer types on the flow and droplet velocity characteristics of ceramic flat-fan nozzles. Turkish J. Agric. Forestry, 40(1), 25-37. https://doi.org/10.3906/tar-1411-140

Sidahmed, M. M. (1996). A theory for predicting the size and velocity of droplets from pressure nozzles. Trans. ASAE, 39(2), 385-391. https://doi.org/10.13031/2013.27513

Snelder, D. J., Masipiquena, M. D., \& De Snoo, G. R. (2008). Risk assessment of pesticide usage by smallholder farmers in the Cagayan Valley (Philippines). Crop Prot., 27(3), 747-762. https://doi.org/10.1016/j.cropro.2007.10.011

Stapper, B. E., Sowa, W. A., \& Samuelsen, G. S. (1992). An experimental study of the effects of liquid properties on the breakup of a two-dimensional liquid sheet. J. Eng. Gas Turbines Power, 114(1), 39-45. https://doi.org/10.1115/1.2906305

Teske, M. E., \& Barry, J. W. (1993). Parametric sensitivity in aerial application. Trans. ASAE, 36(1), 27-33. https://doi.org/10.13031/2013.28310

Teske, M. E., Bird, S. L., Esterly, D. M., Curbishley, T. B., Ray, S. L., \& Perry, S. G. (2002). AgDRIFT: A model for estimating near-field spray drift from aerial applications. Environ. Toxicol. Chem., 21(3), 659-671. https://doi.org/10.1002/etc.5620210327

Teske, M. E., Thistle, H. W., \& Ice, G. G. (2003). Technical advances in modeling aerially applied sprays. Trans. ASAE, 46(4), 985-996. https://doi.org/10.13031/2013.13955

Teske, M. E., Thistle, H. W., \& Riley, C. M. (2018). The evaporation rate of droplets inside a spray cloud. Proc. 14th Intl. Conf. on Liquid Atomization and Spray Systems (ICLASS 2018).

Thistle, H. W., Bonds, J. A. S., Kees, G. J., \& Fritz, B. K. (2017). Evaluation of spray drift from backpack and UTV spraying. Trans. ASABE, 60(1), 41-50. https://doi.org/10.13031/trans.11990

Trayford, R. S., \& Welch, L. W. (1977). Aerial spraying: A simulation of factors influencing the distribution and recovery of liquid droplets. J. Agric. Eng. Res., 22(2), 183-196. https://doi.org/10.1016/0021-8634(77)90062-2

Wang, S., Dorr, G. J., Khashehchi, M., \& He, X. (2015). Performance of selected agricultural spray nozzles using particle image velocimetry. J. Agric. Sci. Tech., 17(3), 601-613. 